\title{
UPAYA MENINGKATKAN KETUNTASAN BELAJAR MATEMATIKA MENGGUNAKAN MODEL PEMBELAJARAN KOOPERATIF TIPE NUMBERED HEADS TOGETHER (NHT) DI SMPN 3 DEPOK SLEMAN TAHUN PELAJARAN 2012/2013
}

\author{
Yeni Rahmawati ES \\ Pendidikan Matematika FKIP Universitas Muhammadiyah Metro \\ Email: yeni.rahmawati1988@yahoo.com
}

\begin{abstract}
The aims of this research were to increase the mastery learning of student by implementation of cooperative Learning type number head together. The method of the reseacrh was Classroom Action Research. The Instrument of data collection used formatif test sheet and photo documentation. Technique of data analysis used qualitative and quantitative analysis. Based on the results of this research showed that through a cooperative learning type Numbered Heads Together (NHT) can increase student mathematics learning completeness VIID class. Increased mastery learning mathematics student looks from the average value of the class, the average value of the final test grade students cycle known to increase students' mastery learning mathematics in the first cycle was 74.3 to 76.2 in the second cycle. In addition, the number of students who received grades greater than or equal to 75 also increased from the first cycle is 16 students or 50\% to 25 students or $78.12 \%$.
\end{abstract}

Keywords: cooperative learning, mastery learning, $N H T$

\section{PENDAHULUAN}

Matematika

merupakan

sumber dari ilmu yang lain. Hal ini sesuai yang dikemukakan oleh Suherman dkk (2001) bahwa matematika sebagai ratu atau ibunya ilmu dimaksudkan matematika adalah sebagai sumber dari ilmu lain.. Disadari atau tidak, matematika sangat penting sebagai alat bantu dalam memecahkan masalah-masalah dalam kehidupan sehari-hari.

Menyadari pentingnya peranan matematika, pemerintah telah melakukan berbagai upaya untuk meningkatkan hasil belajar matematika melalui peningkatan kualitas pembelajaran matematika. Salah satu cara yang dilakukan oleh pemerintah adalah dengan penerapan kurikulum KTSP. KTSP menuntut perubahan paradigma dalam pendidikan dan pembelajaran, yang awalnya orientasi pembelajaran berpusat pada guru kemudian beralih berpusat pada siswa. Meskipun kurikulum KTSP sudah cukup lama diberlakukan sejak tahun 
2006, pada kenyataannya sampai saat ini kualitas pendidikan matematika dapat dikatakan belum menunjukkan hasil yang memuaskan. Salah satu hasilnya adalah belum tuntasnya siswa dalam pembelajaran matematika. Berdasarkan hasil penelitian tingkat nasional, khususnya di kabupaten Sleman tepatnya di SMPN 3 Depok pada materi aljabar, daya serap siswa terhadap materi tersebut belum mencapai $75 \%$. Selain itu, berdasarkan nilai MID semester ganjil tahun pelajaran 2012/2013 untuk kelas VIID ternyata sebagian besar siswa belum tuntas dalam belajar matematika. Siswa dikatakan tuntas dalam belajar apabila nilai siswa mencapai KKM yang telah ditentukan. Khusus mata pelajaran matematika di SMPN 3 depok, KKM yang ditetapkan adalah 75 . Siswa kelas VIID yang tuntas hanya ada 6 siswa dari 32 siswa. Ini berarti ada 26 siswa atau $81,25 \%$ siswa yang belum tuntas. Ini mengindikasikan bahwa ketuntasan belajar matematika di kelas VIID masih dalam kategori rendah.

Siswa dalam pembelajaran matematika dituntut untuk dapat mencapai ketuntasan pada setiap kompetensi dasarnya. Oleh karena itu, guru dan siswa harus bekerja keras agar dapat mencapai tujuan pembelajaran matematika yang telah ditetapkan. Guru semakin dituntut untuk profesional menjalankan tugasnya yang harus menghantarkan siswanya mencapai ketuntasan belajar. Selain itu, guru harus bisa mengarahkan siswa mencapai tujuan pembelajaran.

Idealnya, jika siswa belum mencapai ketuntasan pada suatu materi maka tidak boleh melanjutkan ke materi berikutnya sebelum materi tersebut dikuasai secara tuntas. Namun pada kenyataannya, walaupun siswa belum mencapai ketuntasan belajar, guru tetap melanjutkan ke materi berikutnya. Keterbatasan waktu yang dimiliki guru dalam menyampaikan materi pelajaran merupakan alasan utama mengapa hal tersebut dilakukan. Oleh karena itu, diperlukan suatu metode pembelajaran yang dapat membantu tercapainya ketuntasan belajar siswa khususnya mata pelajaran matematika.

Santrock

menyatakan, hanya ketika murid berada dalam kelompok kooperatiflah mereka kemungkinan tidak akan memilih bermain, interaksi positif sesama teman, dan perasaan positif tentang keputusan mereka adalah faktor motivasi di balik pilihan murid untuk berada dalam kelompok belajar bersama. Murid sekolah menengah mendapatkan manfaat yang lebih besar dan mengekspresikan motivasi intrinsik yang lebih untuk mempelajari konsep aljabar ketika mereka belajar dalam kelompok ketimbang belajar sendiri-sendiri. 
Mengatasi masalah-masalah yang disebutkan di atas, maka diperlukan suasana belajar yang aktif, efektif, dan kreatif, dan menyenangkan, agar siswa senantiasa meningkatkan ketuntasan dalam belajar matematika. Salah satunya adalah dengan menerapkan model pembelajaran kooperatif.

Model

pembelajaran kooperatif merupakan model pembelajaran yang dilaksanakan dengan sistem berkelompok. Menurut Roger \& David (Anita Lie, 2002) tidak semua belajar kelompok bisa dianggap pembelajaran kooperatif. Untuk mencapai hasil yang maksimal, lima unsur model pembelajaran kooperatif harus diterapkan yaitu:

a. Saling ketergantungan positif

b. Tanggung jawab perseorangan

c. Tatap muka

d. Komunikasi antar kelompok

e. Evaluasi proses kelompok Dalam pembelajaran kooperatif, guru perlu mengetahui sintak model pembelajaran kooperatif. Adapun sintak model pembelajaran kooperatif adalah sebagai berikut.

Tabel 1 Sintak model pembelajaran kooperatif

\begin{tabular}{|c|l|l|}
\hline Langkah & \multicolumn{1}{|c|}{ Fase-Fase } & \multicolumn{1}{c|}{ Aktivitas Guru } \\
\hline 1 & $\begin{array}{l}\text { Menyampaikan tujuan dan } \\
\text { mempersiapkan siswa }\end{array}$ & $\begin{array}{l}\text { Guru menyampaikan tujuan } \\
\text { pembelajaran dan mengo- } \\
\text { munikasikan kompetensi yang } \\
\text { akan dicapai serta mempersiapkan } \\
\text { siswa }\end{array}$ \\
\hline 2 & Menyajikan informasi & $\begin{array}{l}\text { Guru menyajikan informasi } \\
\text { kepada siswa secar verbal }\end{array}$ \\
\hline 3 & $\begin{array}{l}\text { Mengorganisasikan siswa } \\
\text { dalam kelompok- } \\
\text { kelompok }\end{array}$ & $\begin{array}{l}\text { Guru memberikan penjelasan } \\
\text { kepada siswa tentang tata cara } \\
\text { pembentukan tim belajar dan } \\
\text { membantu kelompok melakukan } \\
\text { tansisi yang efisien }\end{array}$ \\
\hline 4 & $\begin{array}{l}\text { Membantu kerja kelompok } \\
\text { dan belajar }\end{array}$ & $\begin{array}{l}\text { Guru membantu kelompok- } \\
\text { kelompok belajar selama peserta } \\
\text { siswa mengerjakan tugasnya }\end{array}$ \\
\hline 5 & Evaluasi & $\begin{array}{l}\text { Guru mengevaluasi hasil belajar } \\
\text { tentang materi pembelajaran yang } \\
\text { telah dilaksanakan }\end{array}$ \\
\hline 6 & Memberikan penghargaan & $\begin{array}{l}\text { Guru memberikan penghargaan } \\
\text { hasil belajar individual dan } \\
\text { kelompok }\end{array}$ \\
\hline
\end{tabular}

(Agus Suprijono, 2009) 
Berdasarkan uraian di atas, dapat disimpulkan bahwa pembelajaran kooperatif merupakan pembelajaran yang banyak memberikan waktu untuk aktivitas siswa dalam mempelajari materi yang diberikan. Dalam kelompok-kelompok kecil siswa akan lebih banyak terlibat, saling membantu dan bertanggung jawab terhadap penguasaan materi untuk dapat memaksimalkan pencapaian hasil belajar.

Menurut Anita Lie (2002) ada tiga hal penting yang perlu diperhatikan dalam pengelolaan kelas model pembelajaran kooperatif, yakni: pengelompokan, semangat pembelajaran kooperatif, dan penataan ruang kelas. Hal ini sangat penting karena bertujuan untuk membina siswa dalam mengembangkan niat dan kiat bekerja sama dan berinteraksi dengan siswa yang lain. Model pembelajaran kooperatif yang dimaksudkan dalam penelitian ini adalah pembelajaran kooperatif dengan menggunakan tipe Numbered Heads Together (NHT). Menurut Trianto (2009) NHT atau kepala nomor berstruktur adalah merupakan jenis pembelajaran kooperatif yang dirancang untuk mempengaruhi pola interaksi siswa dan sebagai alternative terhadap struktur kelas tradisional. Tipe NHT ini pertama kali dikembangkan oleh Spencer Kagen dengan melibatkan para siswa dalam menelaah bahan yang tercakup dalam suatu pelajaran dan mengecek pemahaman mereka terhadap isi pelajaran. Tipe NHT ini dapat digunakan untuk memecahkan masalah yang tingkat kesulitannya terbatas. Selain itu, NHT memberi kesempatan kepada siswa untuk membagikan ide-ide dan mempertimbangkan jawaban yang paling tepat.

Ciri khas dari NHT adalah guru hanya menunjuk seorang siswa yang mewakili kelompoknya untuk menyampaikan hasil diskusi. Dalam menunjuk siswa tersebut, guru menyebutkan nomor tertentu tanpa memberi tahu terlebih dahulu siapa yang akan mewakili kelompok tersebut. Slavin (2005) menjelaskan bahwa belajar kooperatif menekankan pada tujuan dan keberhasilan kelompok, yang hanya dapat dicapai jika semua anggota kelompok mencapai tujuan atau penguasaan materi

Adapun langkah dalam pembelajaran NHT antara lain yaitu: (Trianto, 2009)

1. Langkah 1: Penomoran. Guru membagi siswa ke dalam kelompok beranggotakan 3-5 orang dan setiap anggota kelompok diberi nomor 1-5.

2. Langkah 2: Mengajukan pertanyaan. Guru mengajukan sebuah pertanyaan kepada siswa. Pertanyaan dapat bervariasi. Pertanyaan dapat spesifik dan dalam bentuk 
ISSN 2442-5419 Vol. 4, No. 2 (2015) 84-94

kalimat tanya atau bentuk arahan

3. Langkah 3: Berpikir bersama. Siswa menyatukan pendapatnya terhadap jawaban pertanyaan itu dan meyakinkan tiap anggota dalam timnya mengetahui jawaban itu.

4. Langkah 4: Menjawab. Guru memanggil siswa dengan nomor tertentu, kemudian siswa yang nomornya sesuai mengacungkan tangannya dan mencoba untuk menjawab pertanyaan untuk seluruh kelas.

Kelebihan pembelajaran tipe NHT, yaitu:

a. Setiap siswa menjadi siap semua.

b. Dapat melakukan diskusi dengan sungguh-sungguh.

c. Siswa yang pandai dapat membantu siswa yang kurang pandai.

Berdasarkan langkahlangkah pembelajaran yang tersebut di atas, sangat memungkinkan bagi siswa ketuntasan belajar matematika menjadi meningkat. Dengan demikian ada peningkatan ketuntasan belajar matematika jika dibandingkan dengan pembelajaran sebelumnya.

METODE PENELITIAN

Penelitian ini merupakan jenis Penelitian Tindakan Kelas
(PTK). PTK mencakup empat langkah, yaitu: 1) perencanaan (planning), 2) tindakan (acting), 3) pengamatan (observing), refleksi (reflecting).

Penelitian ini dilaksanakan di kelas SMPN 3 depok, Sleman. Sedangkan untuk waktunya pada semester ganjil tepatnya bulan November tahun pelajaran 2012/2013. Subyek penelitian tindakan kelas ini adalah kelas VIID semester ganjil tahun pelajaran 2012/2013.

Teknil pengumpulan data menggunakan teknik tes dan non tes. Teknik tes digunakan untuk mengumpulkan data yang bersifat kuantitatif berupa nilai-nilai siswa, untuk mengetahui ketuntasan belajar siswa. Bentuk tes yang digunakan adalah uraian berjumlah 5 soal. Teknik non tes berupa dokumentasi berupa foto.

\section{HASIL PENELITIAN DAN PEMBAHASAN}

Penelitian ini terdiri dari 2 siklus dimana setiap siklus terdiri dari 2 kali pertemuan. Tes akhir siklus dilakukan pada pertemuan ketiga. Berikut ini akan disajikan daftar pelaksanaan penelitian yang telah dilakukan di kelas VIID SMPN 3 Depok pada kompetensi dasar menggunakan konsep aljabar dalam pemecahan masalah aritmetika sosial yang sederhana 
ISSN 2442-5419 Vol. 4, No. 2 (2015) 84-94

Tabel 1 Jadwal Pelaksanaan Penelitian

\begin{tabular}{|c|c|c|c|}
\hline Hari/tanggal & Siklus & Pert & Materi \\
\hline Kamis, 8 Nov 2012 & I & 1 & $\begin{array}{l}\text { 1. Menghitung nilai keseluruhan } \\
\text { 2. Menghitung nilai per-unit } \\
\text { 3. Menghitung nilai sebagian } \\
\text { 4. Menentukan harga jual } \\
\text { 5. Menentukan harga beli } \\
\text { 6. Menentukan besar laba dan rugi }\end{array}$ \\
\hline Sabtu, 10 Nov 2012 & I & 2 & $\begin{array}{l}\text { 1. Menentukan persentase laba dan } \\
\text { rugi } \\
\text { 2. Menentukan harga pembelian } \\
\text { berdasarkan persentase untung } \\
\text { atau rugi } \\
\text { 3. Menentukan harga penjualan } \\
\text { berdasarkan persentase untung }\end{array}$ \\
\hline Selasa, 13 Nov 2012 & $\mathrm{I}$ & 3 & Evaluasi siklus I \\
\hline Sabtu, 17 Nov 2012 & II & 1 & $\begin{array}{l}\text { 1. menentukan rabat } \\
\text { 2. menentukan bruto } \\
\text { 3. menentukan netto } \\
\text { 4. menentukan tara }\end{array}$ \\
\hline Selasa, 20 Nov 2012 & II & 2 & $\begin{array}{l}\text { 1. Menentukan besar bunga } \\
\text { tabungan } \\
\text { 2. Menentukan besar PPh dan PPN }\end{array}$ \\
\hline Kamis, 22 Nov 2012 & II & 3 & Evaluasi siklus II \\
\hline
\end{tabular}

1. Hasil Penelitian Tindakan Kelas Siklus I

Proses pembelajaran pada siklus I berlangsung dalam dua pertemuan.

Pertemuan berlangsung selama 2 X 40 menit. Sedangkan evaluasi berlangsung selama 60 menit pada pertemuan ketiga. Setelah pembelajaran pada siklus I selesai, guru melakukan evaluasi. Evaluasi dilakukan dengan memberikan tes dalam bentuk esai sebanyak 5 soal. Data hasil evaluasi siklus I dapat dilihat pada tabel berikut. 
Tabel 2 Hasil Evaluasi Siklus I

\begin{tabular}{|c|c|l|c|c|}
\hline N0 & NIS & \multicolumn{1}{|c|}{ NAMA } & UH 1 & Ket \\
\hline 1 & 5328 & Achmad Baehaki & 68 & BT \\
\hline 2 & 5329 & Ade Ari Rama & 70 & BT \\
\hline 3 & 5330 & Afifah Aulia Rachmawati & 46 & BT \\
\hline 4 & 5331 & Agista Aredhea Farozi & 76 & T \\
\hline 5 & 5332 & Angelina Avida Galuh A & 64 & BT \\
\hline 6 & 5333 & Annis Sekar Pertiwi & 58 & BT \\
\hline 7 & 5334 & Annisa Permata Sari & 64 & BT \\
\hline 8 & 5335 & Bagas Putra Pratama & 26 & BT \\
\hline 9 & 5336 & Berli Indah Puspita & 76 & T \\
\hline 10 & 5337 & Cakrawisesa Birawa P & 42 & BT \\
\hline 11 & 5338 & Clara Wahyu Candrarini & 72 & BT \\
\hline 12 & 5339 & Crisnanto Ajhi Saputro & 64 & BT \\
\hline 13 & 5340 & Diemas Ridho Nugroho & 64 & BT \\
\hline 14 & 5341 & Dina Christnari Amelia P & 68 & BT \\
\hline 15 & 5342 & Eka Nurmalita Oktaviani & 88 & T \\
\hline 16 & 5343 & Fatkha Hadi Yahya & 100 & T \\
\hline 17 & 5344 & Furi Fajar Utami & 84 & T \\
\hline 18 & 5345 & Ganesha Amrina Wijaya & 100 & T \\
\hline 19 & 5346 & Ketut Arya Wikranta S & 92 & T \\
\hline 20 & 5347 & Kezia Amantha & 76 & T \\
\hline 21 & 5348 & Khansa Pharamitha D & 76 & T \\
\hline 22 & 5349 & M. Aditya Ramadhani & 100 & T \\
\hline 23 & 5350 & M. Imam Dakhilullah & 72 & BT \\
\hline 24 & 5351 & Nabilla Risqi Fatimah B & 88 & T \\
\hline 25 & 5352 & Nurul Lisa Andriani & 60 & BT \\
\hline 26 & 5353 & Oktavia Dian Milanti & 82 & T \\
\hline 27 & 5354 & Raihana Hikmawati H & 76 & T \\
\hline 28 & 5355 & Refifareli & 84 & T \\
\hline 29 & 5356 & Ria Trisnawati & 100 & T \\
\hline 30 & 5357 & Riri Safitri & 72 & BT \\
\hline 31 & 5358 & Tasya Nadhifa Gunawan & 100 & T \\
\hline 32 & 5359 & Yuliana Indah Saskia & 70 & BT \\
\hline & & Rata-rata & 74,3 & \\
\hline & & Skor terendah & 100 & \\
\hline & & Skor tertinggi & \\
\hline
\end{tabular}


ISSN 2442-5419 Vol. 4, No. 2 (2015) 84-94

Tabel 3 Persentase Ketuntasan Belajar Siklus I

\begin{tabular}{|c|c|c|c|c|c|c|}
\hline \multicolumn{3}{|c|}{ Jumlah Siswa } & \multicolumn{3}{c|}{ Nilai } \\
\hline $\begin{array}{c}\text { Peserta } \\
\text { UH }\end{array}$ & $\begin{array}{c}\text { Nilai } \\
\geq 75\end{array}$ & $\begin{array}{c}\text { Nilai } \\
<75\end{array}$ & $\begin{array}{c}\text { Nilai } \\
\text { Terendah }\end{array}$ & $\begin{array}{c}\text { Nilai } \\
\text { Tertinggi }\end{array}$ & $\begin{array}{c}\text { Rata- } \\
\text { rata } \\
\text { Kelas }\end{array}$ & $\begin{array}{c}\text { Persentase } \\
\text { ketuntasan }\end{array}$ \\
\hline 32 & 16 & 16 & 26 & 100 & 74,3 & $50 \%$ \\
\hline
\end{tabular}

Berdasarkan tabel di atas dapat dilihat bahwa nilai rata-rata kelas yang diperoleh pada siklus I adalah 74,3 dengan persentase kentutasan belajar siswa adalah $50 \%$. Berdasarkan hasil observasi dan diskusi dengan observer, kekurangan-kekurangan yang terdapat pada siklus I akan dilakukan tindakan perbaikan pada siklus II yaitu:

1) Merencanakan alokasi waktu yang lebih efektif sehingga antara waktu yang tersedia dengan materi seimbang.

2) Guru mengoptimalkan pengelolaan kelas menjadi lebih baik sehingga memungkinkan seluruh nomor dapat memprsenatsikan hasil diskusi
3) Guru menegur atau memberi sanksi bagi siswa yang tidak mengikuti aturan dalam pembelajaran kooperatif tipe NHT

2. Hasil Penelitian Tindakan Kelas Siklus II

Proses pembelajaran pada siklus II berlangsung dalam dua pertemuan. Pertemuan berlangsung selama 2 X 40 menit. Sedangkan evaluasi berlangsung selama 60 menit pada pertemuan ketiga. Setelah pembelajaran pada siklus I selesai, guru melakukan evaluasi. Evaluasi dilakukan dengan memberikan tes dalam bentuk esai sebanyak 5 soal. Data hasil evaluasi siklus II dapat dilihat pada tabel berikut. 
Tabel 4 Hasil Evaluasi Siklus II

\begin{tabular}{|c|c|l|c|c|}
\hline N0 & NIS & \multicolumn{1}{|c|}{ NAMA } & UH 2 & Ket \\
\hline 1 & 5328 & Achmad Baehaki & 76 & $\mathrm{~T}$ \\
\hline 2 & 5329 & Ade Ari Rama & 86 & $\mathrm{~T}$ \\
\hline 3 & 5330 & Afifah Aulia Rachmawati & 72 & $\mathrm{BT}$ \\
\hline 4 & 5331 & Agista Aredhea Farozi & 76 & $\mathrm{~T}$ \\
\hline 5 & 5332 & Angelina Avida Galuh A & 70 & $\mathrm{BT}$ \\
\hline 6 & 5333 & Annis Sekar Pertiwi & 68 & $\mathrm{BT}$ \\
\hline 7 & 5334 & Annisa Permata Sari & 74 & $\mathrm{BT}$ \\
\hline 8 & 5335 & Bagas Putra Pratama & 20 & $\mathrm{BT}$ \\
\hline 9 & 5336 & Berli Indah Puspita & 48 & $\mathrm{BT}$ \\
\hline 10 & 5337 & Cakrawisesa Birawa P & 76 & $\mathrm{~T}$ \\
\hline 11 & 5338 & Clara Wahyu Candrarini & 78 & $\mathrm{~T}$ \\
\hline 12 & 5339 & Crisnanto Ajhi Saputro & 76 & $\mathrm{~T}$ \\
\hline 13 & 5340 & Diemas Ridho Nugroho & 86 & $\mathrm{~T}$ \\
\hline 14 & 5341 & Dina Christnari Amelia P & 78 & $\mathrm{~T}$ \\
\hline 15 & 5342 & Eka Nurmalita Oktaviani & 78 & $\mathrm{~T}$ \\
\hline 16 & 5343 & Fatkha Hadi Yahya & 90 & $\mathrm{~T}$ \\
\hline 17 & 5344 & Furi Fajar Utami & 84 & $\mathrm{~T}$ \\
\hline 18 & 5345 & Ganesha Amrina Wijaya & 85 & $\mathrm{~T}$ \\
\hline 19 & 5346 & Ketut Arya Wikranta S & 82 & $\mathrm{~T}$ \\
\hline 20 & 5347 & Kezia Amantha & 78 & $\mathrm{~T}$ \\
\hline 21 & 5348 & Khansa Pharamitha D & 86 & $\mathrm{~T}$ \\
\hline 22 & 5349 & M. Aditya Ramadhani & 86 & $\mathrm{~T}$ \\
\hline 23 & 5350 & M. Imam Dakhilullah & 76 & $\mathrm{~T}$ \\
\hline 24 & 5351 & Nabilla Risqi Fatimah B & 80 & $\mathrm{~T}$ \\
\hline 25 & 5352 & Nurul Lisa Andriani & 74 & $\mathrm{BT}$ \\
\hline 26 & 5353 & Oktavia Dian Milanti & 84 & $\mathrm{~T}$ \\
\hline 27 & 5354 & Raihana Hikmawati H & 78 & $\mathrm{~T}$ \\
\hline 28 & 5355 & Refifareli & 86 & $\mathrm{~T}$ \\
\hline 29 & 5356 & Ria Trisnawati & 78 & $\mathrm{~T}$ \\
\hline 30 & 5357 & Riri Safitri & 76 & $\mathrm{~T}$ \\
\hline 31 & 5358 & Tasya Nadhifa Gunawan & 76 & $\mathrm{~T}$ \\
\hline 32 & 5359 & Yuliana Indah Saskia & 76 & $\mathrm{~T}$ \\
\hline & & Rata-rata & 76,2 & \\
\hline & & Skor terendah & \\
\hline & & Skor tertinggi & \\
\hline
\end{tabular}


ISSN 2442-5419 Vol. 4, No. 2 (2015) 84-94

Tabel 5 Persentase Ketuntasan Belajar Siklus II

\begin{tabular}{|c|c|c|c|c|c|c|}
\hline \multicolumn{3}{|c|}{ Jumlah Siswa } & \multicolumn{3}{|c|}{ Nilai } & \multirow[b]{2}{*}{$\begin{array}{l}\text { Persentase } \\
\text { ketuntasan }\end{array}$} \\
\hline $\begin{array}{c}\text { Peserta } \\
\text { UH }\end{array}$ & $\begin{array}{l}\text { Nilai } \\
\geq 75\end{array}$ & $\begin{array}{l}\text { Nilai } \\
<75\end{array}$ & $\begin{array}{c}\text { Nilai } \\
\text { Terendah }\end{array}$ & $\begin{array}{c}\text { Nilai } \\
\text { Tertinggi }\end{array}$ & $\begin{array}{l}\text { Rata- } \\
\text { rata } \\
\text { Kelas }\end{array}$ & \\
\hline 32 & 25 & 7 & 20 & 70 & 76,2 & $78,12 \%$ \\
\hline
\end{tabular}

Berdasarkan tabel di atas dapat dilihat bahwa nilai rata-rata kelas yang diperoleh pada siklus II adalah 76,2 dengan persentase kentutasan belajar siswa adalah $78,12 \%$. Karena indikator keberhasilan yang peneliti tentukan sudah tercapai dari segi ketuntasan belajar siswa maka dapat dikatakan penelitian ini sudah berhasil, sehingga penelitian dicukupkan sampai siklus II.

Pelaksanaan siklus I untuk pertemuan pertama dan kedua dilaksanakan berdasarkan rencana pelaksanaan pembelajaran yang telah disusun sesuai dengan model pembelajaran kooperatif tipe NHT. Setelah pelaksanaan pembelajaran sebanyak dua pertemuan, dilakukan evaluasi untuk siklus I. Berdasarkan evaluasi siklus I diperoleh nilai rata-rata kelas sebesar 74,3 dengan persentase ketuntasan belajar $50 \%$. Nilai tertinggi yang diperoleh siswa adalah 100 dan nilai terendah adalah 26. Dari 32 siswa hanya 16 siswa yang memperoleh nilai di atas KKM dan sisanya sebanyak 16 siswa memperoleh nilai di bawah KKM. Hasil yang diperoleh pada siklus I masih tergolong cukup rendah atau belum memenuhi indikator keberhasilan pada penelitian ini.

Proses pembelajaran pada siklus II dilaksanakan seperti siklus I, tetapi guru melakukan perbaikan-perbaikan berdasarkan kekurangan-kekurangan yang terjadi pada siklus I. Berdasarkan hasil evaluasi siklus II diperoleh nilai rata-rata kelas 76,2 dengan persentase ketuntasan belajar $78,12 \%$. Meningkatnya nilai ketuntasan ini disebabkan karena dari 32 siswa hanya 7 siswa yang memperoleh nilai kurang dari KKM yang telah ditetapkan, sedangkan sisanya sebanyak 25 siswa memperoleh nilai di atas KKM. Peningkatan nilai rata-rata dan persentase ketuntasan pada siklus II terjadi karena pelaksanaan model pembelajaran kooperatif tipe NHT sudah berjalan sesuai dengan rencana yang telah disusun. Terlihat juga adanya peningkatan nilai rata-rata dari siklus I dan siklus II yaitu sebesar $1,9 \%$. Selain itu peningkatan ketuntasan belajar secara klasikan yaitu sebesar $28,12 \%$. Terjadinya peningkatan nilai rata-rata dan ketuntasan belajara secara klasikan ini dapat dijadikan indikator keberhasilan penelitian sehingga 
ISSN 2442-5419 Vol. 4, No. 2 (2015) 84-94

dalam penelitian ini dikatakan berhasil.

\section{KESIMPULAN DAN SARAN}

Berdasarkan hasil penelitian tindakan kelas dan pembahasan yang telah dikemukakan, maka dapat diambil kesimpulan bahwa pembelajaran dengan menggunakan model kooperatif tipe NHT dapat meningkatkan ketuntasan belajar matematika di SMPN 3 depok sleman tahun pelajaran 2012/2013. Meningkatnya ketuntasan belajar ini dapat dilihat dari nilai rata-rata kelas pada tes siklus I sebesar 74,3 meningkat menjadi 76,2 pada siklus II. Secara klasikan ketuntasan belajar siswa kelas VIID meningkat dari $50 \%$ yang memenuhi KKM menjadi 78,12\% yang memenuhi KKM.

Guru dapat menggunakan model pembelajaran kooperatif tipe NHT untuk mengatasi kelemahan pada pembelajaran kooperatif, agar semua anggota bisa aktif dalam kegiatan belajarnya sehingga dapat meningkatkan ketuntasan belajar siswa. Sebaiknya guru selalu berusaha untuk meningkatkan kualitas pembelajaran, agar siswa lebih tertarik dan senang belajar matematika.

\section{DAFTAR PUSTAKA}

Anita Lie. 2002. Cooperative learning. Jakarta: Grasindo.

Agus Suprijono. 2009. Cooperative learning teori dan aplikasi paikem. Yogyakarta: Pustaka pelajar

Santrock, W. J. 2011. Psikologi pendidikan. (Terjemahan Tri Wibowo B.S) Jakarta: Kencana. (Buku asli diterbitkan tahun 2004).

Slavin, Robert E. (2005). Cooperative Learning: theory, research and practice (Terjemahan N.Yusron.).London: Allymand Bacon. Buku asli diterbitkan tahun 2005.

Suherman, dkk. 2001. Strategi pembelajaran matematika kontemporer. Bandung: UPI.

Trianto. 2009. Mendesain model pembelajaran inovatifprogresif. Jakarta: Kencana Prenada media 